\title{
Dodgy kebabs everywhere? Variety of Worldviews and Regulatory Change
}

Martin Lodge

Department of Government

London School of Economics

Houghton Street

London WC2A $2 \mathrm{AE}$

Kai Wegrich

Hertie School of Governance

Friedrichstr. 180

10117 Berlin

Gail McElroy

Department of Political Science

Trinity College Dublin

Dublin 2

May 2009, 9,876 words 


\begin{abstract}
Grid-group cultural theory has attracted considerable interest in the study of risk regulation. There has, however, been a lack of a systematic interest in its claims and in methodological issues. In this paper, we present five claims that are drawn from cultural theory and assess them in the light of one single case: failure in meat inspections in Germany. These claims are assessed through the analysis of argumentation as recorded in newspapers. In the light of its empirical findings, this paper argues that the claims and the methodology employed offer a promising avenue for further work to investigate the usefulness of this particular theoretical approach.
\end{abstract}

Key words: cultural theory, regulation, food inspections, Germany 


\section{Introduction}

Three issues occupied German newspapers during the summer of 2006. One obvious and anticipated one was the staging of the football world cup and the (unanticipated) success of the German national team. The second event was the hunt for, and eventual killing, of a disturbed brown bear. The bear, quickly christened 'Bruno' (JJ1 in official language), had strolled into Bavarian territory from his 'home ground' in the Italian Alps. For over a month, 'Bruno' successfully evaded various and numerous attempts at tracking him down until a 'license to kill' was issued by the responsible Bavarian minister. The bear was killed the next day, provoking substantial criticism against the minister. The third issue raising public concern and involving the very same Bavarian minister was Gammelfleisch, the revelation that putrid meat had been systematically sold across Europe by a number of meat distribution companies, mainly from Bavaria, but also from other parts of Germany.

Besides being of concern for consumers of kebabs past and present ${ }^{1}$, Gammelfleisch offers an useful case for investigating underlying claims made by grid-group cultural theory and its predictions about patterns of change in the context of an evocative moment and crisis (for cultural theory, see Thompson et al. 1990). Cultural theory has received considerable attention (but mixed praise) in the study of risk perceptions and has been utilized in studies interested in control instruments within and by government (Hood et al. 1999, 2004). However, much of the work in cultural theory has remained at the abstract level, with analysis confined for the most part to broad-based empirical observations. This paper seeks to move to a more systematic 'audit' of argumentation over time, thereby advancing an agenda initiated by the late Aaron Wildavsky (Swedlow 2002: 273-5, Thompson 1997). ${ }^{2}$

\footnotetext{
${ }^{1}$ Kebabs are arguably the most popular German national dish, on par with chicken tikka masala in Britain and hot dogs in the US.

2 A number of labels exist; for convenience and readability we choose 'cultural theory', rather than 'grid-group cultural theory', 'CT', 'grid group theory' or other variants. We do not seek to enter into wider debates regarding the 'true essence' of cultural theory, but suggest that the Wildavskyinterpretation represents one mainstream variant.
} 
The evocative moment of interest here, Gammelfleisch, the failure of German meat inspections to identify putrid meat sold (primarily) to kebab take-aways, is undoubtedly interesting in itself in terms of a political-administrative crisis situation and in terms of the literature on the 'contested governance' of food safety in Europe (Ansell and Vogel 2006). The key purpose of this paper, however, is to derive a number of claims from the principal arguments that lie at the heart of cultural theory in order to put this particular theoretical lens 'to work'. We do so by developing a systematic and general analysis of argumentation, as recorded in newspapers. In other words, this paper is largely intended to systematically apply cultural theory by addressing issues of testing and measurement and to elaborate on the problems inherent in undertaking such a venture. It is therefore not primarily interested in explaining Gammelfleisch as such (although we do briefly comment on these matters in the conclusion).

This paper progresses in four steps. First, we develop five claims, derived from key arguments associated with cultural theory. Second, we briefly introduce the German context of meat inspection and the key events associated with Gammelfleisch.

Third, we present our results. Fourth, and finally, we conclude by reflecting on our findings and our methodology, what these findings tell us about cultural theory and how cultural theory has contributed to our understanding of Gammelfleisch.

\section{Putting cultural theory to work}

One of cultural theory's particular attractions has been its claim to parsimony, dividing culture into four worldviews, biases or 'social solidarities' (hierarchy, egalitarianism, individualism, fatalism) that are in continuous contention and contestation with each other. ${ }^{3}$ Each worldview is characterized by fundamentally different understandings about the nature of the world, contrasting ways of structuring social relations, and underlying cause-effect relationships - leading to

\footnotetext{
${ }^{3}$ We ignore the 'hermit' in this discussion. Unlike the other four, 'hermits' exclude themselves from social life, thereby offering no account of how to relate to other worldviews.
} 
contrasting diagnoses of policy problems and advocacy of policy solutions. Selfinterest, according to cultural theory, is embedded in particular worldviews - and thus the availability of particular strategies is embedded in distinct institutional settings (Wildavsky 1987, Majone 1989: 2). Any institutional arrangement, such as a regulatory regime, has to be understood as a temporary settlement that reflects the dominance of one worldview over others (or a coalition of worldviews over others). As such, therefore, these concerns of cultural theory relate directly to other approaches that emphasise the importance of policy beliefs and issue images, such as 'advocacy coalition frameworks' (Sabatier and Weible 2007) or 'punctuated equilibrium theory' (True, Jones and Baumgartner 2007).

In the world of cultural theory, change occurs through processes of surprise and disappointment. Experiences of surprise or disappointment (i.e. the failure of assumed cause-effect relationships to alleviate a problem when applied) encourages the formation of alternative coalitions that offer competing 'solutions' to problems, leading eventually to the replacement of the original institutional settlement (see 6, 2004, 2003). Inherent conflict means that coalitions are inherently unstable.

Instability, 'hunting around' and change are therefore less surprising than stability. Cultural theory suggests that temporary stability is achieved through the formation of inclusive coalitions that create 'clumsy solutions' (Verweij et al. 2006) or 'hybrids' (Hood 1998: 233-40, Thompson and Ellis 1997: 4-10, 6 2003). Others point to an inherent temporality, as tensions will eventually lead to the destruction of any particular hybrid (Thompson et al. 1990: 86-93, Lodge and Wegrich 2005a: 420, Lodge and Wegrich 2005b).

Table 1 illustrates the well-known 2x2 exposition of cultural theory with its four types - based on the distinction between (high or low) rule (or grid) - and (high or low) group-boundedness. Each cell in Table 1 also contains information on how regulatory approaches reflect particular worldviews, as outlined in Hood (1996, 1998, and developed in Hood et al. 1999, 2001, 2004). As noted, the study of control, risk and regulation has been one of the principal fields in which cultural 
theory has found popularity in recent decades. In this paper we continue further down this route by moving from categorising regulatory approaches according to the cultural theory typology to actual measurement of responses, while acknowledging that cultural theory may be applied in a host of other sub-fields in political science.

\section{Table 1 about here}

While cultural theory has attracted considerable interest in the measurement of risk perceptions through the use of surveys (e.g. Dake 1991, Sjöberg 1998), and was included in the Oxford Handbook of Contextual Political Analysis (Thompson, Verweij and Ellis 2006), it has received less attention in the general study of public policy. Paul Sabatier (1999: 11), for example, noted that cultural theory was 'too incomplete and unclear' to deserve inclusion in the first edition of Theories of the Policy Process. ${ }^{4}$ Grid-group cultural theory may not be of a predictive kind, but the broad level of abstraction and generality in which the claims are put forward and how the evidence is presented are somewhat problematic. Cultural theory seems very good at putting different perspectives on past events, making competing rationalities explicit and pointing to broad mechanisms of change, but there is scope for more methodological efforts in terms of developing testable claims and observable implications.

Some of the problems in such an undertaking are inherent in grid-group cultural theory itself - issues that relate to wider debates about what constitutes 'science'. Wildavsky, Ellis and Thompson argued that cultural theory would be falsified if similar institutions generated different worldviews, or where different institutional contexts generated similar cultural biases (Thompson et al 1990: 273). Assuming an

\footnotetext{
${ }^{4}$ Exceptions are Hood 1996, 1998, and Hoppe 2007, Hoppe and Peterse 1993. See also Swedlow 2006: xviii-xx, Thompson et al 1999. For overview of the substantial opus associated with cultural theory, see http://ponderingmind.org/cultural_theory/cultural-theory-bibliography/ (last accessed 21 March 2009). Sabatier did not repeat this claim in the second edition of his Theories of the Policy Process.
} 
inherent 'socio-cultural variability' within any institutional setting, even such a claim appears challenging: Given the inherent instability predicted by cultural theory, comparison and generalization appear problematic as different responses may reflect the distinct temporality that underlines interactive policy processes. Possibly the most predictive component of grid-group theory is the argument that system breakdown or failure occurs due to disappointment and blind spots of particular worldviews $(6,2003)$. A second key claim is that institutional arrangements reflect and are therefore reactive to shifts in dominant worldviews.

The rest of this section develops five claims that have been derived from grid-group cultural theory which are then linked to a particular methodology. This perspective is then utilized to analyze one particular case, namely Gammelfleisch. In doing so, this paper invites criticisms. One is that this is an unfaithful, 'old-fashioned' or partial representation of cultural theory. Given the ambitions of this paper, the development of a method in the light of key claims, we cannot fully take into account the multiple (and often competing) strains and interpretations that have developed over the past two decades. This paper is about developing cultural theory in a testable fashion and not about re-defining cultural theory itself, although we do attempt to do justice to the principal arguments within the field. Second, the paper is not about testing cultural theory against alternative and competing theoretical explanations of a particular event (e.g. rational choice or behavioural accounts). Such juxtaposition of theories can only be achieved after a method for testing cultural theory is developed.

\section{Developing claims}

In order to establish observable and testable implications of any theory, we must first agree on the central claims of the theory itself. Given the various theoretical treatments of cultural theory that have developed over the years, this is no easy undertaking. Here we limit our analysis to what we consider the least controversial exegesis, as set out above. Thus, based on claims of 'socio-cultural variability', 
continuous contestation, and institutions as embodiment of dominant worldviews, this paper investigates the following five claims ${ }^{5}$

C1: All four worldviews are represented when it comes to diagnosing failure and advocating solutions

C2: Institutions filter and structure argumentation about regulatory regime change

C3: Over time, given sustained criticism (and pressure), argumentation will diversify

C4: Actors put forward hybrid arguments to encourage a 'coalitional' hunting around for solutions

C5: When regulatory reforms occur, regulatory instruments will reflect the dominant worldviews at that particular time

$\mathrm{C} 1$ reflects on the core claim ('socio-cultural variability') that all cultural worldviews are present, albeit to varying degrees, in any given social system at any particular time (Thompson et al 1990, Thompson and Ellis 1997).

According to $\mathrm{C} 2$, institutions offer a significant moderating role against 'hunting around' patterns. Institutions are said to promote particular worldviews over others (Douglas 1986). Accordingly, political systems resemble 'processing machines' in which issues are processed in predictable and recurring ways. Hence, similar patterns (or life cycles) of argumentation are reproduced over the course of the various Gammelfleisch episodes. Put differently, according to C2, we would expect argumentation to reflect a 'corner-seeking' pattern in which corporate actors seek to reassure their worldviews by biased information processing (Thompson and Wildavsky 1986). If C2 was to hold, we would expect to witness similar argumentation patterns over the course of the various Gammelfleisch episodes under consideration.

\footnotetext{
${ }^{5}$ We choose the word 'claims' and the abbreviation C instead of the conventional term 'hypothesis' and ' $\mathrm{H}$ ' in order to avoid confusion with the use of $\mathrm{H}$ as abbreviation of 'hierarchy' used later in our analysis.
} 
In contrast, if $\mathrm{C} 3$ was to hold, then the observed patterns would suggest a significant change between various episodes that would be expressed not only in the higher degree of exposure (or total amount of argumentation), but also by a higher degree of diversity in the types of arguments being made and, potentially, the emergence of a new dominant pattern. $\mathrm{C} 3$ predicts staged responses to criticism in the policy environment (Laughlin 1991, Wildavsky 1998). Sustained criticism or evidence that assumed cause-effect relationships appear to be false encourages change in argumentation. We therefore regard the four social solidarities not as fixed cohorts attached to fundamental underlying beliefs, but rather as a differentiated population, where some actors are more attached to particular worldviews than others, with some changing worldviews over time in the light of disappointment.

C4 assumes that hybrids are strategic devices for the construction of new coalitions (Thompson et al 1990: 86-93, more strongly by 62003 , 2004). Actors prefer the 'purity' of their own worldview, but realize the advantages of temporary coalitions with other worldviews. Therefore, coalitions emerge around hybrids. As such, this claim appears uncontroversial. However, a number of problems arise. One concerns the number of theoretical and practical possibilities of hybrid formation, even in the relatively parsimonious world of only four pure worldviews. On the one hand, one could argue that it will be difficult for anyone to express views that attract followers of all four worldviews at the same time, given the inherent tensions and contradictions this would display. On the other hand, the same word can be attractive to different worldviews for different reasons at the very same time (Coyle and Wildavsky 1987) The latter issue raises not only problems regarding coding (discussed below), but also suggests that the number of hybrid combinations may be considerable. At this point, we do not explore this problem further, but instead investigate the existence of hybrids in the first place and concentrate on the hybrids 
we observe that are drawn from two worldviews. ${ }^{6}$ A third problem is that we bring corporate actors (see Scharpf 1997:60-2) into the analysis when some cultural theory inspired analysis has moved towards the study of 'collectives', namely 'social solidarities' (Verweij et al 2006). However, we need an empirical based view as to whether alleged 'egalitarians' (such as Greens) argue according to stereotype, and how key actors seek (or not) to build coalitions or to defend their preferred state of the world.

C5 is based on the argument that dominant coalitions will seek to embed their preferred policy options through institutional choices. Institutional choice is therefore reactive to change in dominant worldviews. Such institutional arrangements are therefore likely to reflect, what Verweij and colleagues (2006) call 'elegant solutions' which represent the dominance of any one (or two-way) worldview. They can also be assumed to be 'inelegant' and 'clumsy' (therefore potentially more stable) should there be no straightforward dominance observable.

\section{Case selection and method}

These claims are investigated in the particular context of Gammelfleisch, a crisis linked to an evocative moment that makes patterns predicted by cultural theory particularly prominent. The perception of 'crisis' - triggered in particular by the recurring nature of the problem in combination with an evocative term - allowed for the emergence of widespread argumentation. The analysis was conducted through the following steps. First of all, using Nexis, newspaper articles for the time period February 2001 to April 2007 containing the words Gammelfleisch (between November 2005 and November 2006) or Fleischskandal (February 2001 to November 2005) were analyzed according to particular claims being made by

\footnotetext{
${ }^{6}$ Furthermore, Thompson et al (1990: 92) suggest that any other than a two-way coalition is likely to be both 'rare' and 'extremely short-lived'. Two-way hybrids have also been discussed in the existing literature on control (Hood 1998: 235-40).
} 
key actors. ${ }^{7}$ A total of 410 claims was entered into a database including date, source, author of the claim and its target (where appropriate). These claims were analyzed according to their cultural biases and coded according to their cultural type. We concentrated on 377 claims relating to the two major scandals taking place in the time periods October 2005-January 2006 and August 2006-January 2007 (120 and 257 claims respectively).

'Auditing' argumentation through the analysis of the media is arguably problematic due to issues of bias. Journalists and newspapers could be seen as members of one single social solidarity, or they could be filtering out or accentuating certain contributions. However, Nexis, in the case of Germany, offers a good spread of political opinion and ownership as represented in the newspaper market. We are therefore confident that our sample does not significantly suppress particular (elite) views (and our elite interviews confirmed that we had captured the key actors). In fact, looking at an evocative moment in which sub-domains are in disequilibrium should facilitate our confidence that the sample is not just reflecting dominant actors. In an ideal world, one would also code other media output (especially radio and TV), however, in a highly differentiated and federal broadcasting and TV market, such an undertaking would be even more onerous and open to accusations of bias than restricting ourselves to nationally significant print media. In other words, there is no reason to expect systematic bias in our sample.

Furthermore, there is an issue about the 'presence' of a claim in the print media and the prominence and impact of such claims. While a claim on a front page headline might be more 'important' than a claim hidden in a minor article somewhere on the inside pages, taking account of such differences is complex and would involve a series of additional assumptions as to how to weight salience (page number, article

\footnotetext{
7 The total amount of examined articles was 822. The word Gammelfleisch first appeared in newspaper reports in November 2005. We have used 'Fleischskandal' to cover the earlier eight months. Lexis Nexis excludes the Frankfurter Allgemeine Zeitung, but includes Welt, Berliner Zeitung, Frankfurter Rundschau, Süddeutsche Zeitung, Berliner Morgenpost, Tageszeitung, Der Spiegel and Focus.
} 
length, number of claims per article, 'slow news days' etc). Any attempt at weighting different criteria may involve more arbitrary biases than treating each claim as equally important.

Coding is inherently associated with a number of methodological problems; most of all, this method is vulnerable to coder bias, both at the stage of extracting claims from newspaper reports and at the stage of coding itself. In order to address these problems of bias, the analysis was conducted independently by two researchers and then moderated. There was a relatively high inter-coder reliability of about 0.8 . In addition, the different claims were also categorized (via moderation between two researchers) within their different cultural 'types' in order to allow for comparison within worldviews and also to make particular choices transparent and also to allow for more in-depth analysis.

The coding frame is illustrated in the Appendix. Claims were classified according to the grid group dimensions of cultural theory. Building on the seminal work by Christopher Hood (Hood 1998, Hood et al. 1999, 2004), claims were linked to hierarchy when these implied the potential improvement of controls via enhanced authority (for example, by reordering of authority, improved anticipative instruments and management, as well as sanctions). In contrast, claims were associated with fatalism when these either advocated elements of surprise and unpredictability as effective means of control or offered a lament on the impossibility of controlling capitalist food processing and production. Claims defined as representing individualism advocate market-related processes that enhance individual choice or the autonomy of market participants (such as through a reliance on self-regulation), while egalitarianism-related claims point to the demand for 'high group' processes, such as increased 'professionalism', networktype 'governance' and enhanced forms of participation. Hybrids were identified when a single statement included more than one cultural claim. 
Allocating policy claims to particular worldviews is in itself contestable and needs to reflect the specific institutional context in which actors make claims. To further understand institutional context, we conducted 20 interviews across all key actors at Land and federal level. For example, in this analysis the advocacy for enhanced provisions regarding 'whistleblowers' has been classified as a fatalist response given that this is a process relying on unpredictable and anonymous tip-offs (a low group/high grid response). This choice contrasts, for example, with Christopher Hood's classification of 'whistleblowers' as an egalitarian instrument (Hood 1998: 26). Interviewees supported the classification of whistleblowing as a fatalist response. For example, one leading senior civil servant and 'food inspection professional' spoke out against whistle blowing as it violated the (high group) professional standards of food inspections:

'I think this [whistle blowing] is completely out of order.'

Similarly, 'transparency' is commonly associated with different worldviews, ranging from rule-type hierarchist arguments, to the egalitarian 'town hall' type of transparency to individualist-type 'information enhancing' transparency instruments (Hood 2006). What has been defined as 'product/consumer transparency' in the coding frame relates to individualist (low grid/low group) 'information-enhancing' instruments, especially labelling. Again, this classification was supported unanimously by interviewees. Similarly, the call for stronger 'professional norms' is often regarded as a hierarchical response, but we identify 'professional norms' with an emphasis on professional conduct (not rules) and peer-review - as being of an 'egalitarian' type (i.e. largely being of a high group/low grid type). Two other choices that deserve to be noted include our decision to classify arguments emphasizing the importance of surprise and 'undercover' inspections, as fatalist 'unannounced inspections' (F3), whereas where the emphasis was on 'stronger control', including a stress on unpredictability in the same statement, then it was classified as 'unannounced oversight' of the hierarchy and fatalist hybrid type (H\&F1). 
Finally, the analysis of the formal institutional regime and any change it experienced relied on formal government documentation, and our twenty semistructured elite interviews at the Land and federal level. Having set out the claims that are at the heart of this paper and illustrated methodological choices, we now move to a brief analysis of the German food inspection regime and of events surrounding the Gammelfleisch crisis.

\section{Food inspection regulation and Gammelfleisch}

The issue of 'bad' meat in Germany has gone through three largely separate 'attention cycles' since 2000. Wider issues regarding the quality of food and its inspection were raised when BSE (mad cow disease) was detected in 2000, shortly after ministers and officials had assured the German public that the country was BSE-free. Then in May 2005, a further scandal (generally referred to as Fleischskandal) erupted when it was discovered that staff in a large supermarket chain were relabelling out of date minced meat. This incident led to changes at the organizational level of the supermarket chain in question but, interestingly, not to calls for legislative or regulatory change. In contrast, the two individual meat scandals that are the focus of this paper - one in late 2005, and the other emerging in September 2006, led to widespread calls for legislative and regulatory changes. These two latter scandals emerged in the context of the discovery by non-food inspectors (i.e. the police and customs officials) of meat deemed unfit for human consumption and evidence that relabelled meat had entered the human food chain.

The Gammelfleisch episodes challenged a regime that reflected the core principles of German public administration writ large. Food inspection reflected very typical German administrative arrangements, involving a complex mix of European legislation, federal framework legislation (in particular, the Lebensmittel- und Futtermittelgesetzbuch $)^{8}$ and actual enforcement activities conducted by the Länder.

\footnotetext{
8 Other legislation and regulation related to food hygiene, food labelling, food inspection procedures and specific food-related provisions, among others, for example, for milk and fatty foods and minced meat.
} 
Additionally, among the German Länder, administrative arrangements varied to some extent. But, in its basic form, food inspection was delegated to the local level. Land governments acted as oversight bodies for local enforcement activities - the volume of enforcement activity was determined in intergovernmental agreements across Länder (based on population numbers rather than volume of food production). Furthermore, the overall system of food inspection kept veterinarians separate from food inspectors, while police and customs police were also involved in surveying the food domain. Finally, the vertical and horizontal fragmentation of inspection responsibilities was complicated by ongoing changes in food inspection - largely due to cutbacks - although detection rates remained broadly stable (BVL 2006).

Countering this systemic fragmentation across all aspects of the regulatory regime from information gathering to standard setting to behaviour modification were a number of 'coordination' devices. These ranged from professional associations for food inspectors and veterinarians to procedural guidelines (with legal standing), such as the Allgemeine Verwaltungsvorschrift über die Grundsätze der Durchführung der amtlichen Überwachung lebensmittelrechtlicher und weinrechtlicher Vorschriften (AVV Rüb) implemented in December $2004 .{ }^{9}$ Beforehand, there had been no federal-wide standards regarding food inspection and enforcement activities. The AVV Rüb prescribed a shift towards a 'risk-based' policy in which primary reliance was placed on self-regulation and an inspection intensity that was supposed to reflect the 'risky-ness' of the product and the respective firm's capacity to cope with regulatory standards.

The AVV Rüb and changes at the Land level were partly driven by a changing legal environment originating at the European Union level, especially EU-provisions that came into force during the early and mid-2000s. One central theme at the EU level

\footnotetext{
${ }^{9}$ An AVV (Allgemeine Verwaltungsvorschrift) represented a federal procedural guideline that needed to be agreed in the Bundesrat, the second legislative chamber representing the executives of the subnational governments (Länder).
} 
over the past decade has been the increasing significance of prescribed standards, in particular regarding consumer transparency via labelling provisions, but also concerning the enforcement of regulatory standards in the field of inspection. As part of the EU's 'hygiene package', a risk-based approach was prescribed for food safety inspections and monitoring and reporting requirements were established (882/2004/EU, taking effect in January 2006). This followed the earlier General Principles that were to guide food inspections (178/2002/EU, taking effect in 2005) The perception that German food safety regulation was a moving target throughout the mid-2000s was largely driven by EU-law transposition activities - that broadly followed the wider international move in meat inspections away from the traditional 'poke and sniff' approach (Coglianese \& Lazer 2003).

Moreover, the field of food inspection was confronted with a growing internationalization and specialization of food production and, more significantly, processing, while consumer distrust following 'mad cow disease' increased. On the other hand, attempts by the Red-Green coalition to strengthen consumer protection elements in the food safety regulatory regime in 2002 (in the wake of outrage over BSE) failed due to opposition by the Länder in the Bundesrat (dominated at the time by Christian-Democrat led governments). A watered-down version of this earlier consumer protection law was reintroduced in late 2005 and approved by the Bundestag and the Bundesrat in 2007.

Overall, the German food inspection regime could be interpreted as an inherently 'hierarchical' activity in that inspectors backed by legal sanctions conducted regular control visits. However, inspection was also associated with some egalitarian elements, notably in the presence of 'professional' norms in terms of inspection styles and legal understandings, as well as in the reliance on professional 'selfcontrol' by companies. In addition, although career trajectories pointed to a high relational distance between inspectors and the inspected, there were nevertheless widespread accusations that long-standing relationships at the local level were encouraging lenient controls. To counter this, demands for more 'transparency' in 
inspection reports and increased product information became increasingly prominent. These demands fitted wider advocacy for the advanced legal rights of consumers.

The issue of putrid meat, initially under the heading of Fleischskandal, was prompted by the revelation that meat deemed inappropriate for human consumption had entered the food chain. This so-called K3 meat represented a 'new' market following provisions introduced in the wake of BSE, namely that certain meat residues were deemed unfit for human consumption and should only be used for animal food (whereas $\mathrm{K} 1$ and $\mathrm{K} 2$ were to be destroyed immediately). ${ }^{10}$ Given its 'newness' and as this type meat did not constitute 'food', this sector did not fall under the established regulatory regimes for food inspections. The company was accused of re-labelling these $\mathrm{K} 3$ animal parts, especially by transporting the meat across European borders in order to reduce traceability, and of introducing them into the human food chain. These activities were again not revealed through food inspections but came to light during an investigation by the federal customs police. At the same time, relabelled meat - way beyond its use-by date - was discovered in various storage facilities across Germany. In other cases, frozen poultry meat was defrosted, 'enhanced' in appearance by the addition of water and sold as 'fresh meat'. In December 2005, federal and Land governments agreed on a joint 10-point programme to advance information exchange across administrative units and to enhance control activities. The federal minister announced a reform of the consumer information law, building on measures that had been rejected by the Christian Democrats and Liberals in the Bundesrat in 2002, as noted. This version was supposed to enhance control activities and transparency. The Bavarian government established a special unit for food safety.

\footnotetext{
${ }^{10}$ Directive 2002/1774 EC. The new classification scheme led to an emergence of a K3-industry, Germany was estimated to have over 180 'K3 firms', just under a third of which located in Bavaria (Stern, 13 October 2005)
} 
A few months later, the Gammelfleisch case was triggered by an anonymous call by a mushroom picker who had discovered incriminating documents in a forest in late August 2006. Subsequently, the police raided a meat storage facility near Munich and located significant amounts of putrid meat that had escaped discovery during earlier 'normal' food inspections. Elsewhere in Bavaria, meat was confiscated whose 'use by' date had expired over four years previously. It was later revealed that the company had delivered meat, in particular kebab meat whose spicing allowed for the disguising of rank smell and taste, across Germany and Europe. ${ }^{11}$ Further inspections across Germany detected similar activities. The owner of the firm at the centre of the debacle, already faced with a substantial debt burden, committed suicide. Meanwhile, the federal government, in particular the minister for agriculture and consumer protection, Horst Seehofer, blamed the Bavarian government for insufficient enforcement. The political conflict was particularly heated despite involving politicians from the same (christian democrat) political party at both the federal and Land level (CSU). Länder governments were accused of enthusiastically embracing new standards and commitments without actually providing sufficient resources to advance control. On 7 September 2006, little over a week following the first media headlines, the federal and Land ministers for consumer protection agreed on a 'framework agreement' (a 13 point programme) for a revised 'food inspection regime'. This involved a commitment towards shared understandings of quality management, increased joint usage of information technology and labelling and certification demands for food products, but also an emphasis on the importance of each company's self-regulatory capacities and the continuation of the existing allocation of jurisdiction across levels of government.

At the federal level, the lack of enforcement activity by Land administrations was criticized and changes to the federal competition law were considered, in particular the demand to prohibit the sale of meat 'below production price' (to tackle alleged dumping). This related to the claim that wrongdoing was a consequence of the

11 The meat, if properly cooked, was deemed not to pose a serious risk to human health. 
increasingly low margins in the food business given price competition in the German retail sector, driven by discount retailers and consumer preferences ('Geiz ist geil' ('frugality is sexy')). However, as with the 'framework agreement' between federal and Land governments, hardly anything that had not been discussed before could be detected in these legislative proposals, whether in terms of information provision regarding companies failing safety inspections (called 'consumer transparency', which granted individuals the right to access official inspection reports) or consultation. One novelty, however, was the inclusion of provisions that required ongoing evaluation of the effectiveness of the regulatory regime(s).

\section{Gammelfleisch and argumentation patterns}

Having set out the underlying food inspection regimes and the background to the Fleischskandal and the Gammelfleisch-scandal, we now turn to an analysis of the various claims, as set out above.

\section{C1: All four worldviews are represented when it comes to diagnosing failure and advocating solutions}

\section{Table 2 about here}

Table 2 provides for a descriptive breakdown of the different claims during the two meat scandals. It also suggests that the second cycle of Gammelfleisch of September 2006 witnessed a far higher number of claims. All four 'pure' worldviews are present in the argumentation surrounding meat scandals throughout the two periods. It is also noticeable how dominant hierarchy remains across time. ${ }^{12}$ Figure 1 traces the number of hierarchical claims over time and contrasts these with the total number of other claims over time. It shows how hierarchy dominates argumentation throughout the two periods.

\footnotetext{
12 The causes of this dominance are beyond the scope of this paper, but require cross-national and cross-sectoral analysis of similar food crisis.
} 


\section{Figure 1 about here}

Figure 1 and Table 2 point to a clear dominance of hierarchy within the overall set of claims, amounting to nearly 60 percent, with the other three 'pure' worldviews being relatively similar in proportion. The choice of 'whistleblower' as a fatalist argument is decisive for the ranking among these three other pure worldviews as it represents 18 of the total of 37 (48 percent) fatalist arguments. Whistleblowerrelated claims are equally distributed across the time periods and therefore apart from our ranking, it would not change the dynamics of our analysis (and would not challenge the dominance of hierarchy).

Purely fatalist arguments advocate random or surprise inspections or point to the pointlessness of control initiatives in light of low price competition and capitalist market forces. Egalitarian approaches tend to demand higher professional standards for food inspectors and networked information exchange. Hierarchist approaches advocate higher probabilities of detection and tougher sanctions, better regulatory 'techniques' as well as a strengthening of federal competencies. Finally, individualist arguments were characterized by rejection of regulatory interventions, demands for enhanced consumer transparency via product and inspection information or calls for self-regulation. In addition, hierarchy is also prominent among hybrid arguments. It is noteworthy that apart from hierarchy-related hybrids, only the hybrid of egalitarianism and fatalism was present in our analysis.

\section{C2: Institutions filter and structure argumentation about regulatory regime change}

C3: Over time, given sustained criticism (and pressure), argumentation will diversify

In order to investigate more closely whether there has been an institutional recycling of arguments over episodes (C2) or whether there has been a shift or diversification under the sustained pressure of repeated 'failure', Figure 1 and Table 2 compare the two episodes of Gammelfleisch in late 2005 and mid-2006. Patterns 
of argumentation during the various meat-related incidents suggest a continuous dominance of hierarchical claims. In that sense, $\mathrm{C} 2$ seems to be supported. However, this is not to say that the two episodes recycled the same sort of argumentative patterns. There was, despite low numbers, a statistically significant rise of hierarchy-individualist claims over time (based on a standard z-test). ${ }^{13}$ Furthermore, there was also some fluidity within the hierarchical sub-claims - as can be seen in Table 3. Finally, as Figure 1 suggests, the shape of the two 'cycles' looks considerably different.

\section{Table 3 about here}

Table 3 suggests a statistically significant rise over time of arguments that support enhanced resources to support control activities. What is noticeable too is that the arguments relating to a reordering of legal competencies do not receive further support. In the specific political context of Germany, advocacy of 'reordered legal competencies' is widely regarded as typical blame game: federal government represenatives blame the Länder for poor implementation, while the Länder blame poor federal legislation. If blame games were the dominant strategy we would expect to see a far greater incidence of claims that the lack of federal supervisory control was at the root of the Gammelfleisch scandal. Our findings could therefore be seen as a rejection of accounts that would emphasis the significance of 'blame games' during such crisis (Hood 2002).

One potential explanation for the change within the hierarchical argumentation (as well as the decline of fatalist claims) is the difference in problem constellation between the two episodes under investigation, namely the alleged impossibility to control international businesses dealing with $\mathrm{K} 3$ meat versus the problems of inspecting vast coolhouses. It is also noticeable that hierarchy and hierarchyindividualist claims decline sharply following the agreement between federal and

\footnotetext{
${ }^{13}$ More advanced statistical approaches are potentially applicable. However, given the number of claims in our analysis, such an analysis would not establish robust findings.
} 
Land governments in September 2006. Subsequent discoveries of putrid meat trigger a 'hierarchist-fatalist' response. The relative absence and decline of egalitarian arguments is surprising given the stereotype of the German institutional environment as one where mutuality in policy domains is seen as a central component for a functioning multi-layered, co-operative federal system. However, this absence could also be explained by the increasing criticism of traditional German administrative arrangements.

\section{C4: Actors put forward hybrid arguments to encourage a 'coalitional' hunting around for solutions}

$\mathrm{C} 4$ assumed that hybrids were part of a political calculus to establish coalitions across worldviews. If this assumption is correct, then the small amount, in terms of total number and in terms of types, of hybrid-type claims is surprising (11.67\%). This could be related to coding and we offer this finding with the caveat that the sample size is very small. Table 2 showed that it is egalitarian-fatalist claims that are the dominant form of hybrid (40.9\%), in particular this relates to the suggestion that the problem of meat control is due to issues of price competition in a highly competitive retail environment. It is also notable that the distribution of hierarchyrelated hybrids follows the order of 'pure worldviews', again suggesting that egalitarian themes were surprisingly (for the German context) neglected in comparison to other claims.

\section{Table 4 about here}

Although troubled by low number of claims, we have also looked at those (corporate) actors that should be primarily interested in building coalitions. In Table 4 we compare two ministers, the then Bavarian minister Schnappauf (Christian Social Union), the then federal agriculture and consumer affairs minister, Horst Seehofer (similarly, from the Bavarian Christian Social Union) and a combined set of Germany-wide actors that might be classified as 'egalitarians', namely Green 
politicians and the food-interested advocacy group, 'foodwatch'. Two findings stand out. Neither of these three corporate actors utilises hybrids to any significant degree. Second, so-called 'egalitarians' argue in more individualist and hierarchical ways than one would expect. One might argue that supposedly 'egalitarians' exhibit inherent 'socio-cultural variability'. We would argue that this points to the need to explore more extensively the argumentation of different actors before making firstlevel approximations and allocations regarding 'social solidarity'. These actors' argumentation patterns suggest that supposed egalitarians are divided between those that are sceptical against public authority and therefore embrace individualist themes of consumer action, and those that are sceptical against private economic interests, therefore emphasising the importance of public action.

\section{Table 5 about here}

Looking at the distribution of hierarchical sub-claims alone (and again warning against putting too much emphasis into this interpretation given the low numbers involved), Table 5 suggests that the one actor (federal minister Seehofer), whose institutional self-interest should be primarily interested in advancing federal power, does not dominantly utilize such an argument. His claims need to be separated between blame-allocating arguments, accusing Land governments of insufficient enthusiasm in terms of their enforcement activities, and those arguments advocating enhanced federal competencies for food inspections. In this latter mode, Seehofer takes on the appearance of a 'policy entrepreneur', seeking to exploit this 'window of opportunity' to set the agenda with proposals. Equally, this can be interpreted, given the limited constitutional authority of the federal government in this domain, as an attempt at symbolic politics and credit-claiming. Following the agreement with the Land governments, Seehofer's arguments become more interested in demanding better 'technical fixes' and oversight activities, despite some continued multi-level arguments (that however decline in their prominence). 
In contrast to the federal minister, Schnappauf's arguments mostly build on the need for 'technical fixes' (such as Land-level 'task forces') and some defensive arguments (denying the utility of an extension of federal authority and suggesting extended EU-level provisions). Linked to his hierarchist-fatalist argument that controls are inherently failure-prone ${ }^{14}$, Schnappauf appears as a hierarchist whose primary concern is to deny the potential existence of a Land-federal solution that could advance meat safety by concentrating on other hierarchical arguments. His fatalist arguments reflect those of civil servants in the policy domain, stressing the inherent imperfection of any control activity when faced with a large universe of control objects and non-cooperative behaviour among the regulated.

In sum, there is little to suggest that key actors engage in coalitional hunting around through the advocacy of 'hybrid' or 'clumsy' solutions - a view that follows more closely Thompson et al.s (1990) view of the limited extent and viability of coalitions and hybrids, rather than 6's (2004, also arguably Verweij et al's (2007)) view of the widespread search for and stability of coalitions and hyrid policy designs.

\section{C5: When regulatory reforms occur, regulatory instruments reflect the dominant} worldviews at that particular time

Finally, we return to the claim that institutional arrangements reflect and react to dominant worldviews. The claims can be investigated at the broad policy level as well as the more detailed institutional level, namely the evolution of discussions regarding the intergovernmental agreement regulating inspections, the AVV Rüb (noted above).

As discussed, the overall policy domain moved since the late 1990s towards a regulatory regime that emphasizes hierarchical-individual themes of risk-based

\footnotetext{
${ }^{14}$ Man kann nicht jedes Steak kontrollieren' (it is impossible to control every steak).
} 
regulation. The direction of institutional change was supported by the rise of the hierarchy-individualist hybrid worldviews as expressed through argumentation concerning Gammelfleisch. While there was a continued demand for hierarchical (and thus 'state') control (evident through the continued (and rising!) dominance of pure hierarchical claims, the institutional arrangements increasingly reflected an endorsement of individualist themes, namely measures such as consumer protection law, industry self-certification schemes and 'quality management'. In that sense, the analysis cannot be stretched to suggest that argumentation caused institutional choice, but institutional change went certainly not against the direction of argumentation pattern dynamics.

In addition, there were also further developments that added to this perception of a growing legitimacy of individualist themes; for example, the growing attention paid to 'consumer safety benchmarking leagues' generated by consumer associations. This interpretation is supported by interviewees from federal and Land ministries; the widely shared view on Gammelfleisch was that that particular incident provided 'tailwind' for advancing the implementation of internal administrative and regulatory reforms around the idea of risk-based regulation and wider moves towards a more individualist-blend of regulatory control.

The developments at the intergovernmental regulatory level, the AVV Rüb, provide for an inconclusive pattern. As intergovernmental provision initiated by the federal consumer ministry, it required agreement among a majority of Land governments in the Bundesrat (the second legislative chamber representing Land executives). The modified AVV Rüb of November 2007 was a direct result of the initial 13-points plan of September 2006. Besides an emphasis on the strengthening of risk-based regulation at the Land level, the modified AVV Rüb introduced the demand for more rotation among inspectors and a preference for a 'four eye principle' in inspections as well as the creation of cross-Land 'quality-management audit teams' and a more formal cross-Land 'early warning system'. As such, this institutional response reflected a response across three worldviews: fatalist (rotation), hierarchist 
(management audit and early warning system) as well as egalitarian (four eye principle). The absence of individualist themes is notable, but 'transparency' was the key theme of changes introduced earlier in the consumer information law noted above. The changes in the AVV Rüb and wider legislative changes reflected calls for 'better controls' and represented an incremental adaptation of the German administrative system to the idea of risk-based regulation as well as a tighter regulation of the organization and practice of control. In other words, while we cannot claim a 'causal chain' between argumentation patterns and institutional response in the light of ongoing formal changes, these changes certainly did not go against the observed patterns. We therefore cannot reject $\mathrm{C} 5$.

\section{Conclusion}

This conclusion does three things. First, it summarizes the findings. Second, it discusses what the cultural theory lens has added to our understanding of Gammelfleisch as a specific policy episode, and to our understanding of control in the context of German public administration. Third, and finally, we discuss the potential contribution that this analysis can make to the debate regarding cultural theory as a possible mainstream framework for public policy analysis.

Turning to our findings first, Table 3 illustrates how the various claims performed in the case of Gammelfleisch. In general, we find considerable support for the claims derived from cultural theory. Three key findings stand out. One is the dominance of hierarchy within the presence of 'socio-cultural viability', the second the relative absence of hybrids, and third, the generally stronger support for the 'institutional recycling' versus the 'diversification' argument. It was not the aim of this paper to reject or confirm cultural theory against other theoretical/analytical frameworks (see Ostrom \& Ostrom 1997), but to suggest a way in which such an endeavour could be undertaken in the future. Therefore our ambition has been to explore issues of measurement and conceptualisation, rather than issues of theory development. 
Table 3: Summary of findings

\begin{tabular}{|l|l|}
\hline Claim & Support \\
\hline All four worldviews represented & $\begin{array}{l}\text { Yes (but clear dominance of } \\
\text { hierarchy) }\end{array}$ \\
\hline Institutions filter and recycle argumentation patterns & Some support \\
\hline $\begin{array}{l}\text { Argumentation diversifies and changes over time given } \\
\text { sustained pressure }\end{array}$ & Limited support \\
\hline Actors put forward hybrids to build coalitions & No support \\
\hline Institutional change reactive to dominant worldviews & Some support \\
\hline
\end{tabular}

What do the observed patterns tell us about the cultural biases generated within Germany's system of public administration/ executive government? The first insight is that despite the diagnosed prominence of hierarchy, the absence of the 'traditional' 'hierarchy/egalitarianism' hybrid requires further investigation, both across sectors and over a longer time-period - in its most extreme form, the conclusion of this study could be seen as indicating the decline of the traditional understanding of German public administration as 'cooperative' at the expense of more 'individualist' (i.e. consumer sovereignty views). However, such 'flavours' have to be seen within an overall dominance of hierarchist worldviews.

Turning to the contribution of cultural theory (in the way we have operationalised it here), the observed argumentation pattern would come as a surprise of 'normal' observers of German politics that rely on 'national stereotypes', namely because of the absence of a larger percentage of egalitarian claims. More widely, as Gammelfleisch is inherently about policy-making under conditions of high ambiguity, with a diffuse interest constellation (in terms of costs and benefits of any form of regulatory action), the observed patterns could have neither been predicted by interest group-based analysis (that would predict 'capture' by the regulated industry), by mere 'bureaucratic filtering' accounts (predicting that bureaucracies would concentrate on the do-able rather than the important) or by party-based explanations (suggesting partisan differences towards regulation). Furthermore, the observed regulatory changes take place in the absence of 'coercive' prescription. In other words, cultural theory allows us to capture contestation among elites 
regarding the appropriate interpretation as to what a 'risk-based approach' actually means. Put more widely, cultural theory advances our understanding of change in dominant policy images or policy frames.

This paper has suggested that while there is general interest of cultural theory as an analytical device, its utilization in public policy related research has, as yet, not been a major industry, despite a variety of attempts. This paper aims to be of an explorative kind, seeking to develop claims that are related to this theoretical framework, establishing a methodology through which to consider these claims in a non-casual way, and to offer an application (Gammelfleisch). The overall result is certainly not a rejection of the theory, and indeed, there is some support for key claims of cultural theory. While some of the findings mainly support widespread assumptions concerning how 'regulatory scandals' are perceived in the media and how political actors react under these conditions, the analysis informed by cultural theory is able to reveal more nuanced shifts in how public argumentation changes in the medium term in the face of recurring regulatory failures.

This paper sought to make a first methodological step towards giving effect to these ambitions. Much could be said about the weakness (i.e. lack of robustness) of the approach utilized here, given in particular the low number of claims in some categories, and problems of coding bias that are arguably even more problematic than in other coding exercises (such as those for party manifestos). The natural next step would be to explore the methodology in cross-national and cross-sectoral analysis in order to come to a better appreciation of the patterns observed in the Gammelfleisch case, such as the overall dominance of hierarchy. Nevertheless, as this paper was supposed to be explorative, we conclude by suggesting that any analysis of control within government and by government could be greatly improved by taking up the insights of cultural theory, not only as a typology of instruments and policy strategies, but also as a set of underlying theoretical claims that require further investigation. Cultural theory shifts our attention to argumentation between worldviews and the practice of policy; its central attraction 
lies in its interest in plural rationalities and how institutions are 'lived' and debated.

This paper offers one suggestion on how to move discussion about grid-group cultural theory forward, as only advanced methodologies and rigorous evidence selection can establish its overall usefulness in the study of politics and public policy. 


\section{References}

6, P (2004) 'Joined-up government in the western world in comparative perspective' Journal of Public Administration Research and Theory, 14(1): 103-38. 6, P (2003) 'Institutional viability: a neo-Durkheimian theory' Innovation, 16(4): 395-415.

Ansell, C and Vogel, D (2006) 'The contested governance of European food safety regulation' in C. Ansell and D. Vogel (eds) What's the beef? The contested governance of European food safety regulation, Cambridge/Mas., MIT Press. BVL (2006) Jahresbericht Lebensmittelüberwachung 2006, Braunschweig, Bundesamt für Verbraucherschutz und Lebensmittelsicherheit.

Coglianese, C and Lazer, D (2003) 'Management-based regulation: prescribing private management to achieve public goals' Law \& Society Review 37(4): 691-730. Coyle, D and Wildavsky, A (1987) 'Requisites for Radical Reform' Journal of Policy Analysis and Management, 7(1): 1-16.

Dake, K (1991) 'Orienting Dispositions in the Perception of Risk' Journal of CrossCultural Psychology, 22: 61-82.

Douglas, M (1986) How Institutions Think, London, Routledge.

Hood, C (1996) 'Control over Bureaucracy: Cultural Theory and Institutional Variety', Journal of Public Policy, 15(3): 207-230

Hood, C (1998) The Art of the State, Oxford, Oxford University Press Hood, C (2002) 'The Risk Game and the Blame Game' Government \& Opposition, 37(1): 15-37.

Hood, C, Scott, C, James, O, Jones, G and Travers, G (1999) Regulation Inside Government, Oxford, Oxford University Press.

Hood, C, Baldwin, R and Rothstein, H (2001) The Government of Risk, Oxford, Oxford University Press

Hood, C, James, O, Peters, GB and Scott, C (2004/eds) Controlling Modern Government, Cheltenham, Edward Elgar.

Hood, C (2006) 'Transparency in Historical Perspective' in C. Hood and D. Heald (eds) Transparency: the key to better governance?, Oxford, British Academy/ Oxford University Press.

Hoppe, R (2007) 'Applied Cultural Theory' in F. Fischer, G. Miller and M. Sidney (eds) Handbook of Public Policy Analysis, Boca Raton/Florida, CRC Press.

Hoppe, R and Peterse, A (1993) Handling Frozen Fire, Boulder, CO, Westview. Laughlin, R (1991) 'Environmental disturbances and organizational transitions and transformations' Organization Studies, 12(2): 209-32.

Lodge, $\mathrm{M}$ and Wegrich, K (2005a) 'Governing multi-level governance: comparing domain dynamics in German land-local relationships and prisons', Public Administration, 83(2), 417-442.

Lodge, $\mathrm{M}$ and Wegrich, K (2005b) 'Control over government: institutional isomorphism and governance dynamics in German public administration, Policy Studies Journal, 33(2), 213-233 Majone, G (1989) Evidence, Argument \& Persuasion, New Haven, Yale University Press. 
Ostrom, V and Ostrom, E (1997) 'Cultures: Frameworks, Theories and Models' in R.J. Ellis and M. Thompson (eds) Culture Matters, Boulder, Westview.

Sabatier, PA (1997) 'The Need for Better Theories' in P.A. Sabatier (ed.) Theories of the Policy Process, Boulder, CO, Westview, first edition.

Sabatier, PA and Weible, CM (2007) 'The Advocacy Coalition Framework' in P.A. Sabatier (2007) Theories of the Policy Process, Boulder, CO, Westview.

Scharpf, FW (1997) Games Real Actors Play, Boulder, CO, Westview.

Sjöberg, L (1998) 'World views, political attitudes and risk perception' Risk:

Health, Safety \& Environment, 9: 137-52.

Swedlow, B (2006) 'Editor's Introduction' in A. Wildavsky (eds) Cultural Analysis, New Brunswick, New Jersey.

Swedlow, B (2002) 'Toward cultural analysis in policy analysis: picking up where Aaron Wildavsky left off' Journal of Comparative Policy Analysis, 4(3): 267-85.

Thompson, M (1997) 'Rewriting the Precepts of Policy Analysis' in R. Ellis and M. Thompson (eds) Culture Matters, Boulder, Westview Press.

Thompson, M, Grendstad, G and Selle, P (1999) Cultural Theory as Political Science, London, Routledge.

Thompson, M and Ellis, R (1997) 'Introduction' in R. Ellis and M. Thompson (eds) Culture Matters, Boulder, Westview Press.

Thompson, $\mathrm{M}$ and Wildavsky, A (1986) 'A cultural theory of information bias in organizations' Journal of Management Studies, 23(3): 273-86.

Thompson, M, Ellis, R, Wildavky, A (1990) Cultural Theory, Boulder, Col:

Westview Press

Thompson, M, Verweij, M and Ellis, R (2006) 'Why and how culture matters' in R.

Goodin and C. Tilly (eds) Handbook of Contextual Political Analysis, Oxford, Oxford University Press.

True, JL, Jones, BD, and Baumgartner, FR (2007) 'Punctuated-Equilibrium Theory' in P.A. Sabatier (eds) Theories of the Policy Process, Boulder, CO, Westview.

Verweij, M, Douglas, M, Ellis, R, Engel, C, Hendricks, F, Lohmann, S, Ney, S, Rayner, S, and Thompson, M (2006) 'The Case for Clumsiness' in M. Verweij and M. Thompson (2006) Clumsy Solutions for a Complex World, Basingstoke, Palgrave Macmillan.

Wildavsky, A (1998) 'Cultural Pluralism can both Strengthen and Weaken Democracy' in S-K. Chai and B. Swedlow (eds) Culture and Social Theory, New Brunswick/NJ, Transaction Publishers (orig. 1994).

Wildavsky, A (1987) 'Choosing Preferences by Constructing Institutions: A Cultural Theory of Preference Formation' American Political Science Review, 81(1): 3-21. 


\section{Appendix: Coding Frame}

\section{Hierarchy-command and control}

H1: inspection and technical fixes in control/oversight (include early warning system, more resources)

H2: assertion of hierarchical control, hierarchical oversight (task force)/critique of absent hierarchical control

H3: reallocation of legal competencies

$\mathrm{H} 4$ : corruption and capture

H5: need for more intervention and regulation of the market

H6: need for more deterrence and punishment

\section{Fatalism - control through unpredictable processes}

F1: whistleblower

F2: rotation

F3: unannounced inspections

F4: impossible job

F5: powerlessness of individual consumer

F6: problem mafia-type organization

\section{Individualism - control through rivalry and choice}
I1: consumer/product transparency
I2: naming and shaming
I3: self-regulation by firms themselves
I4: no intervention in markets/price signal
I5: product recall
I6: non-state actor controls

\section{Egalitarianism - control through group processes}

E1: professional norms

E2: local and decentralized economy

E3: mutual information exchange

E4: markets encourage cheating/dangers of naming and shaming strategy

\section{Hierarchy and Fatalism}

H\&F1 unannounced oversight/inspections

H\&F2 inevitable black sheep but overall system ok

\section{Hierarchy \& Individualism}

H\&I1: increase in inspections financed by industry

H\&I2: regulated self-regulation

H\&I3: increase relational distance

H\&I4: penalties and transparency

\section{Hierarchy \& Egalitarianism}

H\&E1: localized inspections

H\&E2: persuasion as enforcement strategy

H\&E3: distaste for individual punishment

H\&E4: controls revealed inherent problem

\section{Egalitarianism \& Fatalism}

E\&F1: price competition among supermarkets 
Table 1: Cultural theory and approaches towards regulation

\begin{tabular}{|c|l|l|l|}
\hline \multicolumn{2}{|c|}{} & \multicolumn{2}{|c|}{ Group } \\
\cline { 2 - 4 } & Low & High \\
\hline Grid & High & $\begin{array}{l}\text { Fatalism } \\
\text { Control through unpredictable } \\
\text { processes/Inherent fallibility }\end{array}$ & $\begin{array}{l}\text { Hierarchy } \\
\text { Anticipative solutions, forecasting, and } \\
\text { management, response to enhanced } \\
\text { authority and hierarchical ordering }\end{array}$ \\
\cline { 2 - 4 } & Low & $\begin{array}{l}\text { Individualism } \\
\text { Control through rivalry and } \\
\text { choice, incentives to underpin } \\
\text { market and individual choice } \\
\text { processes }\end{array}$ & $\begin{array}{l}\text { Egalitarianism } \\
\text { Control through group processes, } \\
\text { network style, participation }\end{array}$ \\
\hline
\end{tabular}


Table 2: Summary of claims

\begin{tabular}{|l|l|l|l|l|}
\hline Category Category & $\begin{array}{l}\text { Total Claims } \\
\mathrm{N}\end{array}$ & $\begin{array}{l}\text { Gammel 1 } \\
\%\end{array}$ & $\begin{array}{l}\text { Gammel 2 } \\
\%\end{array}$ & $\begin{array}{l}\text { Difference } \\
\%\end{array}$ \\
\hline Hierarchy & 220 & 56.67 & 59.14 & 2.47 \\
\hline Individualism & 47 & 11.67 & 12.84 & 1.17 \\
\hline Fatalism & 37 & 13.33 & 8.17 & -5.16 \\
\hline Egalitarianism & 29 & 10.00 & 6.61 & -3.39 \\
\hline Hierarchy-Individualism & 11 & 0.00 & 4.28 & $4.28^{*}$ \\
\hline Hierarchy-Fatalism & 9 & 3.33 & 1.95 & -1.38 \\
\hline Hierarchy-Egalitarianism & 6 & 0.83 & 1.95 & 1.12 \\
\hline Egalitarianism-Fatalism & 18 & 4.17 & 5.06 & 0.89 \\
\hline Total Claims (N) & 377 & 120 & 257 & \\
\hline
\end{tabular}

Statistical Significance Level: *0.05\% 
Table 3: Summary of hierarchical sub-claims

\begin{tabular}{|l|l|l|l|l|}
\hline Category & $\begin{array}{l}\text { Total Claims } \\
\mathrm{N}\end{array}$ & $\begin{array}{l}\text { Gammel 1 } \\
\%\end{array}$ & $\begin{array}{l}\text { Gammel 2 } \\
\%\end{array}$ & $\begin{array}{l}\text { Difference } \\
\%\end{array}$ \\
\hline Inspection \&Technical Fixes & 58 & 27.94 & 25.66 & -2.28 \\
\hline Hierarchical Control & 68 & 22.06 & 34.87 & $12.81^{*}$ \\
\hline $\begin{array}{l}\text { Reallocation of Legal } \\
\text { Competencies }\end{array}$ & 46 & 26.47 & 18.42 & -8.05 \\
\hline $\begin{array}{l}\text { Corruption and Capture } \\
\text { Problem }\end{array}$ & 12 & 4.41 & 5.92 & 1.51 \\
\hline $\begin{array}{l}\text { More Intervention \& } \\
\text { Regulation }\end{array}$ & 5 & 2.94 & 1.97 & -0.97 \\
\hline $\begin{array}{l}\text { More Deterrence \& } \\
\text { Punishment }\end{array}$ & 31 & 16.81 & 13.16 & -3.65 \\
\hline \begin{tabular}{l} 
Total Claims \\
\hline
\end{tabular} & 220 & 68 & 152 & \\
\hline
\end{tabular}

Statistical Significance Level: ${ }^{*} 0.1 \%$ 
Table 4: Comparing corporate actors

\begin{tabular}{|l|c|c|l|}
\hline & $\begin{array}{c}\text { Bavarian } \\
\text { Minister } \\
\text { Schnappauf }\end{array}$ & $\begin{array}{c}\text { Federal } \\
\text { Minister } \\
\text { Seehofer }\end{array}$ & 'Egalitarians' \\
\hline Hierarchy & 46.43 & 71.43 & 56.06 \\
\hline Fatalism & 21.43 & 5.71 & 4.55 \\
\hline Egalitarianism & 7.14 & 8.57 & 6.06 \\
\hline Individualism & 7.14 & 11.43 & 25.76 \\
\hline Hierarchy-Fatalism & 10.71 & 2.86 & 1.52 \\
\hline $\begin{array}{l}\text { Hierarchy- } \\
\text { Individualism }\end{array}$ & 7.14 & 0.00 & 1.52 \\
\hline Egalitarian-Fatalism & 0.00 & 0.00 & 3.03 \\
\hline $\begin{array}{l}\text { Hierarchy- } \\
\text { Egalitarianism }\end{array}$ & 0.00 & 0.00 & 1.52 \\
\hline Total Claims & 28 & 35 & 66 \\
\hline
\end{tabular}


Table 5: Comparing hierarchical sub-claims

\begin{tabular}{|l|c|c|l|}
\hline & $\begin{array}{c}\text { Land } \\
\text { Minister } \\
\text { Schnappauf } \\
\%\end{array}$ & $\begin{array}{c}\text { Federal } \\
\text { Minister } \\
\text { Seehofer } \\
\%\end{array}$ & 'Egalitarians' \\
\hline Inspection \&Technical Fixes & 38.46 & 24.00 & 27.03 \\
\hline Hierarchical Control & 15.38 & 20.00 & 35.14 \\
\hline Reallocation of legal competencies & 30.77 & 48.00 & 18.92 \\
\hline Corruption and Capture & 0.00 & 0.00 & 5.41 \\
\hline More Intervention \& Regulation & 0.00 & 0.00 & 0.00 \\
\hline More Deterrence \& Punishment & 15.38 & 8.00 & 13.51 \\
\hline Total Claims & 13 & 25 & 37 \\
\hline
\end{tabular}


Figure 1: Contrasting two episodes of Gammelfleisch
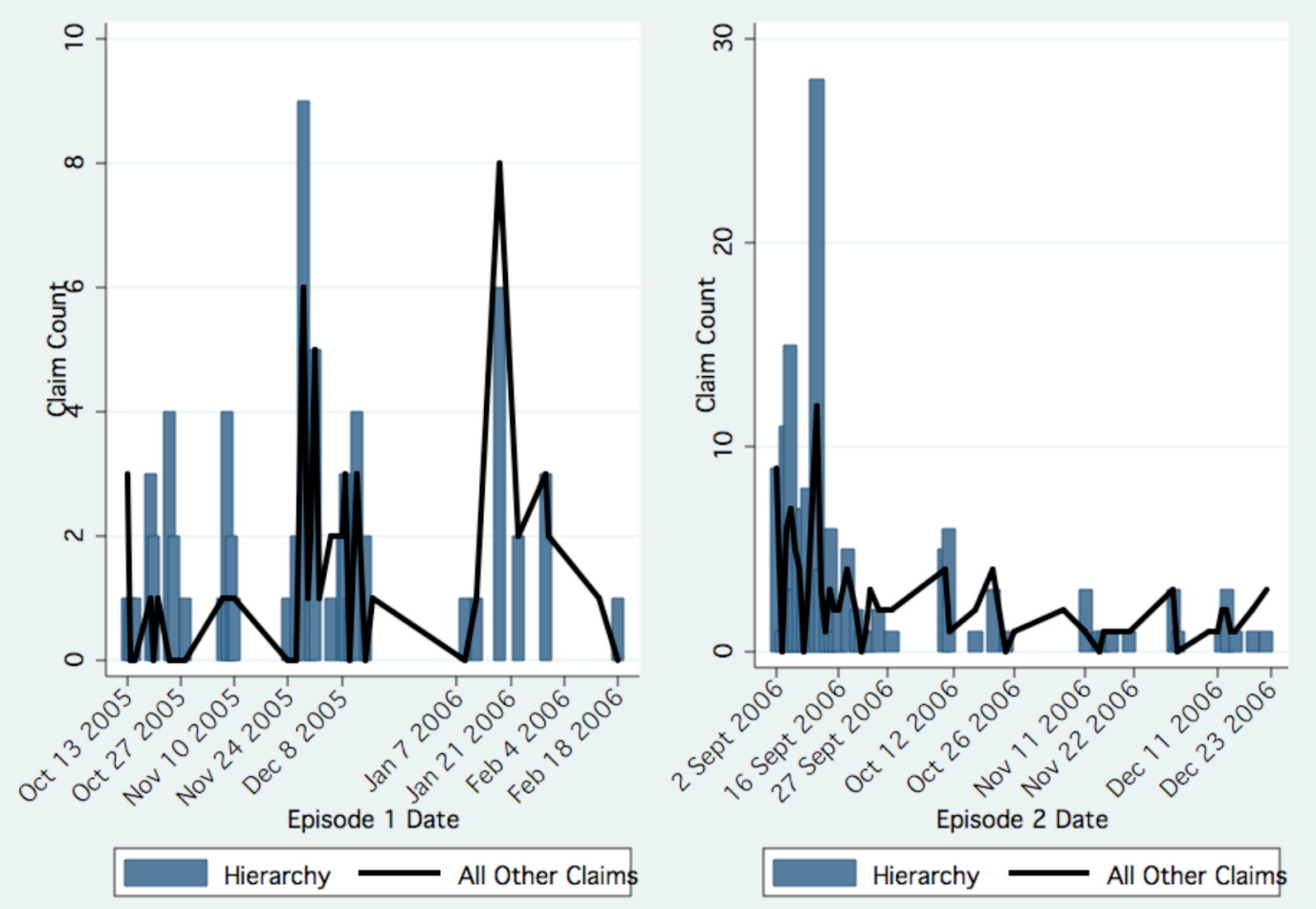